\title{
Estimation of indocyanine green elimination rate constant $k$ and retention rate at 15 min using patient age, weight, bilirubin, and albumin
}

\author{
Ga Yeong Kim - Kyun Seop Bae - Gyu Jeong Noh • \\ Won Ki Min
}

Published online: 24 June 2009

(c) Springer 2009

\section{Erratum to: J Hepatobiliary Pancreat Surg DOI 10.1007/s00534-009-0097-3}

There is an error on line 9 in Results section of the Abstract and line 8 in External validation of the population PK model in a different population in Methods section of the paper body.

The equation now shown as:

The online version of the original article can be found under doi:10.1007/s00534-009-0097-3.

\section{G. Y. Kim}

Department of Laboratory Medicine, Korea University Medical Center, University of Korea College of Medicine,

126-1, Anam-dong, 5-Ga, Seongbuk-Gu, Seoul 136-705,

Republic of Korea

e-mail: elimyh@amc.seoul.kr

\section{K. S. Bae · G. J. Noh}

Department of Clinical Pharmacology and Therapeutics,

Asan Medical Center, University of Ulsan College of Medicine,

388-1 Poongnap-2dong, Songpa-ku, Seoul 138-736,

Republic of Korea

e-mail: ksbae@amc.seoul.kr

\section{G. J. Noh ( $\varangle)$}

Department of Anesthesiology and Pain Medicine,

Asan Medical Center, University of Ulsan College of Medicine,

388-1 Poongnap-2dong, Songpa-ku, Seoul 138-736,

Republic of Korea

e-mail: nohgj@amc.seoul.kr

\section{W. K. Min ( $\square)$}

Department of Laboratory Medicine, Asan Medical Center,

University of Ulsan College of Medicine,

388-1 Poongnap-2dong, Songpa-ku,

Seoul 138-736, Republic of Korea

e-mail:wkmin@amc.seoul.kr
$k=V d_{\mathrm{TV}} / C l_{\mathrm{TV}}$

should read:

$k=C l_{\mathrm{TV}} / V d_{\mathrm{TV}}$

There is another error on line 5-6 in External validation of the population PK model in a different population in Methods section of the paper body.

" $V d_{\mathrm{TV}}$ divided by $C l_{\mathrm{TV}}$ " should be replaced by " $\mathrm{Cl} l_{\mathrm{TV}}$ divided by $V d_{\mathrm{TV}}$." 